REVISTA DE LITERATURA E CULTURA RUSSA

\title{
Iúri Tyniánov e a palavra poética: a poesia no âmbito do Formalismo Russo
}

\section{Yuri Tynianov and the poetic word: poetry in the field of Russian Formalism}

Autor: Aurora Bernardini

Edição: RUS Vol. 11. N 16

Data: Setembro 2020 


\section{Iúri Tyniánov e a palavra poética: a poesia no âmbito do Formalismo Russo}

Resumo: Este ensaio apresenta as principais contribuições da teoria formalista russa para o estudo da poesia. Seu foco incide nos principais achados teóricos de lúri Tyniánov no que se refere à abordagem da linguagem poética. Também aponta analogias e "semelhanças de família" entre as teorias de Tyniánov e as poéticas de Carlos Drummond de Andrade e de Manuel Bandeira.

\begin{abstract}
This essay presents the main contributions of Russian Formalism to the study of poetry. It focus on the theoretical concepts developed by Yuri Tynyanov as an approach to poetic language. Moreover, it presents analogies between Tynyanov's theory of poetic language and the poetics of Carlos Drummond de Andrade and Manuel Bandeira.
\end{abstract}

Palavras-chave: Formalismo Russo; lúri Tyniánov; Poesia; Linguagem poética Keywords: Russian Formalism; Yuri Tynyanov; Poetry; Poetic language 
*Universidade de São Paulo, Programas de Pós-graduação em Letras Estrangeiras e Tradução (Russo) e Teoria Literária e Literatura Comparada da USP. Professora, tradutora, ensaísta e crítica literária; https://orcid. org/0000-0002-2559-7080 ; bernaur2@yahoo.com.br

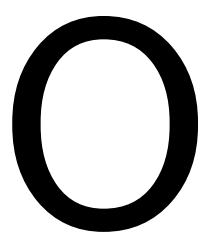

que até hoje surpreende no Formalismo Russo quando se tenta fazer um balanço de sua contribuição nos diferentes setores da indagação literária - e particularmente no campo que escolhemos, o da poesia - é sua incrível atualidade. Desde seu surgimento em $1913^{1}$ passaram-se mais de cem anos e, no entanto, seus achados continuam válidos e, apesar de pressentidos, ainda não de todo explorados. Ainda no século XIX Aleksandr Potebniá, um de seus mais ilustres precursores, seguindo as pegadas de Wilhelm von Humboldt, declara que a poesia é um dos dois modos fundamentais da apreensão do real, ou seja, é aquele do conhecimento "pela mediação da palavra."

E mais - diz ele -, pelo fato de a linguagem tender a libertar-se do jugo do pensamento e lutar pela suprema autonomia da palavra é que a poesia, "a aspiração ideal da linguagem", encontra maiores possibilidades de realização. A diferença entre as duas apreensões do real - a da ciência e a da poesia - não está nos fins que elas perseguem, visto que ambas visam à ordenação da experiência, mas enquanto a ciência se ocuparia com material homogêneo, a poesia dá uma resposta específica a um problema específico.

1 Em 2013 comemorou-se em Moscou o centenário do Formalismo Russo. 0 evento que deu origem ao movimento foi uma palestra que Viktor Chklóvski realizou em 1913. Para maiores detalhes, veja neste mesmo número da RUS o ensaio de Valteir Vaz "A era do estranhamento". 
A ênfase dada à metáfora não era, é claro, novidade em Potebniá. ${ }^{2}$ Já Aristóteles, na Poética, via no "domínio da metáfora" a prova suprema da capacidade de um poeta, prova essa que depois se tornou pedra de toque da teoria romântica da poesia. Mas se a concepção da poesia como discurso autônomo será assumida pelo Formalismo como um de seus pontos-chave, a concepção potebniana da imagem vista como procedimento explicativo, como atalho mental que "substitui uma massa heterogênea de imagens por pequenas unidades intelectuais", virá a ser controvertida pelos formalistas russos, particularmente por Viktor Chklóvski e Roman Jakobson, e substituída por outra praticamente oposta: a função da imagem não consiste em tornar mais acessível o inusitado, mas sim em tornar estranho o habitual, apresentando-o sob uma nova luz.

Enquanto Potebniá indagava sobre a dinâmica semântica da linguagem poética, outro grande precursor, o estudioso russo Aleksandr Vesselóvski (1838-1906), dirigia seus esforços no sentido da fundação de uma História da Literatura como disciplina em si, com fins e métodos bem definidos. Insistia, como ponto de partida, em tentar encontrar um resposta para a questão "o que é literatura?" e, apesar de não ter chegado àquela definição de literaturidade (literaturnost) que Jakobson proporia alguns anos mais tarde, Vesselóvski, em sua Poética Históri$\mathrm{ca}^{4}{ }^{4}$ se detém sobre a questão crucial para os formalistas dos procedimentos artísticos e dos gêneros literários, focalizando

2 POTEBNIÁ, Aleksandr. Из лекций по теории словесности: басня, пословица, поговорка. (Iz lekcij ро teorii slovésnosti: Básnia. Poslóvitsa. Pogovorka (Das palestras sobre teoria da literatura: fábula, provérbio, ditos). Moscou: Vycha chkola, 1984, p. 99.

3 POTEBNIÁ, A. Op. cit. 1984, p. 102.

4 Em 2014, Poética histórica foi traduzida por Pedro Piedras Monroy para a editora Akal, de Madri. Trata-se de uma tradução integral diretamente do russo. 0 volume conta ainda com um elucidativo prefácio assinado por Viktor Jirmúnski. 
a poesia mais do que o poeta e a estrutura objetiva da obra literária mais do que os processos psíquicos que o acompanham.

Se os formalistas, por sua vez, se recusaram a explicar a literatura baseando-se nos processos psicológicos, sociológicos, históricos etc. (não esqueçamos, porém, a questão da consideração das diferentes séries ${ }^{5}$ : histórica, biográfica etc., e a da evolução literária ${ }^{6}$ para as quais, passado o momento polêmico, sempre estiveram atentos), eles também se mostraram arredios quanto a procurar a "literaturidade" no nível da experiência contida na obra de arte literária ou a aceitar a opinião corrente de que o objetivo privilegiado da poesia seriam as emoções, enquanto o da prosa seriam as ideias.

"Não há motivos mais poéticos que outros, e hoje tudo pode servir de material para a poesia"7, escrevia Roman Jakobson em "O que é poesia?", enquanto Iúri Tyniánov, acentuando a fluidez dos limites entre ficção e realidade, insistia no fato de que a diferença entre literatura e não-literatura devia ser procurada não no tema, mas na maneira pela qual esta realidade é apresentada. A mesma questão foi colocada, dentro da literatura, para se estudarem as diferenças entre prosa e poesia.

\footnotetext{
5 A noção de "série" é desenvolvida por lúri Tyniánov no ensaio "O fato literário", em 1924. Pode ser encontrado em Antología del formalismo Ruso y el grupo de Bajtin: polémica, historia y teoría literaria. Trad. e org. de Emil Volek. Madri: Fundamentos, 1992, pp. 205-225.

6 Já a de "evolução literária", também de Tyniánov, está em "Sobre a evolução literária" que saiu em 1927 e é dedicado a Boris Eikhenbaum. Pode ser encontrado em Antología del formalismo Ruso y el grupo de Bajtin: polémica, historia y teoría literaria. Trad. e org. de Emil Volek. Madrid: Fundamentos, 1992, pp. 251-267.
} 
Apesar de Jakobson ter sustentado numa série de trabalhos a conhecida tese de que a poesia tende para a metáfora (associação por semelhança) enquanto a prosa tende para a metonímia (associação por contiguidade), e que a função poética da linguagem implica a ênfase na expressão, está claro que tanto a metáfora quanto a linguagem poética não são o fator constitutivo da poesia. ${ }^{8}$

\section{O papel do ritmo}

Entre outros livros valiosos sobre o assunto, existe um livrinho de Tyniánov que originariamente tem o título de $O$ problema da linguagem em verso, ${ }^{9}$ onde é dada uma explicação às vezes complexa, mas sempre extremamente convincente de como funciona a poesia. É dele que vamos falar um pouco agora. Tomemos como ponto de partida a constatação de Carlos Drummond de Andrade, de que o ritmo é o verdadeiro fator constitutivo da poesia, inclusive, no caso, do próprio verso livre:

[...] Então rasguei aquilo e parti impávido para a poesia de verso livre - na ilusão de que era mesmo livre. Não há verso livre. $O$ verso obedece às leis do ritmo. $O$ verso, para ser verso, tem que ter uma estrutura musical, uma cadência. Não importa que você faça quatorze versos de dez sílabas cada um, divididos em dois quartetos e dois tercetos, ou faça como os ingleses, que usam outra divisão. $O$ verso pode ter dez sílabas na primeira linha, quatro na segunda, seis na terceira. É preciso que essas linhas reunidas formem um conjunto rítmico. É como a música moderna, feita mais de dissonâncias do que de

9 TYNJANOV, Jury. II Problema del Linguaggio Poetico. Milão, Mondadori, 1968. Em português: Iúri Tyniánov. 0 problema da linguagem poética l: o ritmo como elemento construtivo do verso. Rio de Janeiro: Tempo Brasileiro, 1975. lúri Tyniánov. 0 problema da linguagem poética II: o sentido da palavra poética. Rio de Janeiro: Tempo Brasileiro, 1975. 
consonâncias. Isso facilitava muito meu trabalho. ${ }^{10}$

Vejamos qual será a justificativa que disso dá Tyniánov em seu livro.

O que acontece se transcrevermos em prosa o verso livre?

Podem se dar duas ocorrências: $1^{\text {a }}$ - as divisões do verso não coincidem com as divisões sintáticas, devido à disposição gráfica. Bem, ao passar para a prosa, as divisões desaparecerão. De tal modo ficará destruída a unidade da série poética e, mais, juntamente com ela, será destruído outro elemento indicativo, ou seja, precisamente aqueles laços estritos graças aos quais a unidade poética consegue manter, amarradas em si mesmas, as palavras: o caráter compacto da série poética. O ritmo no verso é indicativo justamente pela unidade e pela compressão da série do material do discurso. Esse é o motivo pelo qual o conteúdo quantitativo da série poética é limitado, e - quando o verso é longo demais - ou ele se divide em outras unidades ou perde a noção de seus limites. Em ambos os casos deixa de ter unidade. Os dois elementos referidos, a unidade e a compressão da série poética, dão lugar a um terceiro traço distintivo que é a dinamização do material do discurso. A série discursiva na poesia é mais compacta e mais amarrada do que no discurso comum e evidencia infalivelmente a unidade do verso. Nas formas estabelecidas de versificação, a unidade de medida (pé ou sílaba) será menor que o verso enquanto que, na versificação livre, cada verso será assumido como norma. No caso do verso regular temos então uma dinamização de palavras: cada palavra é objeto, ao mesmo tempo, de várias categorias de discurso (é palavra discursiva, é palavra métrica).

10 Carlos Drummond de Andrade. Entrevista ao "Folhetim" de 03/06/1984 para o Jornal Folha de São Paulo. 
No caso do verso livre tem-se frequentemente a dinamização de grupos, sendo que o grupo pode consistir numa única palavra. Assim, enquanto a unidade e a compressão da série poética impõem uma nova ordem às articulações e aos nexos sintáticos-semânticos (ou, no caso em que a série poética coincida com a unidade gramatical, elas aprofundam e sublinham os momentos dos nexos e das articulações sintático-semânticas), a dinamização do material do discurso leva a uma nítida separação entre palavra poética e palavra comum. 0 sistema de interação entre as tendências da série poética e do conjunto gramatical da palavra métrica e da palavra discursiva assume um papel decisivo. A palavra torna-se um compromisso, uma resultante das duas séries, assim como a frase. A palavra torna-se dificultada e o processo do discurso torna-se secundário. Se, conforme dizíamos, transformarmos em prosa o verso livre em que a série poética não coincida com a série sintática, estaremos violando a unidade e o caráter compacto da série poética, privando-a de sua capacidade de dinamizar o discurso: emergirá o princípio construtivo da prosa e em lugar dos nexos e das articulações do verso, passarão a atuar os nexos e as articulações de natureza sintático-semântica.

$2^{\mathrm{a}}$ - $\mathrm{O}$ que acontece, agora, quando se passa para a prosa o verso livre em que a série coincide com a unidade (ou o conjunto) gramatical? A unidade da série poética é destruída, passando a coincidir com a unidade sintática; o momento de compressão da série poética decai, permanecendo uma ligação marcada entre os membros da unidade sintática, e a poesia acaba por desfazer-se por lhe faltar um de seus traços distintivos: o momento da dinamização do discurso. A série poética, mesmo não perdendo de todo suas características, não será mais poética; no desenvolvimento do material não mais se notará a medida do verso, a sua unidade, e juntamente com ela não terá havido a dinamização da palavra e de seus 
agrupamentos, resultando isso tudo no decaimento do caráter secundário da palavra no verso. O princípio construtivo de qualquer série tem uma força assimilativa e deformante em relação aos fenômenos de uma outra série. $O$ segredo está na subordinação de um momento a outro, e na poesia, contrariamente à prosa, a influência deformante deve ser procurada no ritmo, juntamente com o princípio de associação simultânea dos elementos do discurso.

Veja-se como Manuel Bandeira pressente esse "segredo" numa passagem de Itinerário de Pasárgada:

Cedo compreendi que o bom fraseado não é fraseado redondo, mas aquele em que cada palavra tem uma função precisa, de caráter intelectivo ou puramente musical, e não serve senão à palavra cujos fonemas fazem vibrar cada parcela da frase por suas ressonâncias anteriores e posteriores". ${ }^{11}$

\section{O material da poesia}

Além do problema do ritmo, visto como fator construtivo da poesia, o objeto do livro de Tyniánov é o material de que a poesia é feita e, mais particularmente, "o sentido da palavra no verso". Essa questão não menos complexa, por ele submetida a um exame rigoroso, leva-o a "achados" extremamente esclarecedores. Ele utiliza como exemplo uma série de poemas russos, mas podemos novamente recorrer a Drummond, cuja milagrosa "Procura da Poesia" os sintetiza quase todos. Devido à sua extensão, reproduzimos apenas uma parte dessa procura:

11 BANDEIRA, Manuel. Itinerário de Pasárgada. Rio de Janeiro: Nova Fronteira, 1966, p. 45. Quanto à "desorientação" de Manuel Bandeira em relação às características do verso livre, veja-se na correspondência de Mário de Andrade e Manuel Bandeira, a carta de Bandeira de 30 de março de 1925 (Andrade e Bandeira 2000: 192-194) citada por Paulo Henriques Britto em "O Natural e o Artificial: Algumas Reflexões sobre o Verso Livre." ELyra: Revista Da Rede Internacional Lyracompoetics, (3). Obtido de https://www.elyra.org/index.php/elyra/article/ view/40 
(...) A poesia (não tires poesia das coisas)

Elide sujeito e objeto.

Não dramatizes, não invoques, não indagues. Não percas tempo em mentir.

Não te aborreças.

Teu iate de marfim, teu sapato de diamante, vossas mazurcas e abusões, vossos esqueletos de família desaparecem na curva do tempo, é algo imprestável.

(...) Penetra surdamente no reino das palavras.

Lá estão os poemas que esperam ser escritos.

Estão paralisados, mas não há desespero, há calma e frescura na superfície intata.

Ei-los sós e mudos, em estado de dicionário.

Convive com teus poemas, antes de escrevê-los.

Tem paciência, sê obscuro. Calma, se te provocam.

Espera que cada um se realize e consuma com seu poder de palavra e seu poder de silêncio.

Não forces o poema a desprender-se do limbo.

Não colhas no chão o poema que se perdeu.

Não adules o poema. Aceita-o

como ele aceitará sua forma definitiva e concentrada no espaço.

Chega mais perto e contempla as palavras.

Cada uma

tem mil faces secretas sob a face neutra

e te pergunta, sem interesse pela resposta,

pobre ou terrível, que lhe deres:

Trouxeste a chave?

Repara:

ermas de melodia e conceito

elas se refugiaram na noite, as palavras.

Ainda úmidas e impregnadas de sono,

rolam num rio difícil e se transformam em desprezo. ${ }^{12}$ 
Afora a questão do ritmo e a unidade do verso, coincidindo e não coincidindo com a unidade lógico-sintática, que é visível nas várias estrofes do poema, aí estão, na ordem em que foram mencionados, a imagem tornando estranho o habitual ("Teu iate de marfim, teu sapato de diamante") e funcionando como metáfora e metonímia ao mesmo tempo. Lá está, em todos os nãos, a afirmação da literaturidade e a suspensão ("não te aborreças" etc.), das outras séries. Fica quase didaticamente explicada, no poema, a ausência de motivos privilegiados ("não tires poesia das coisas") e a soberania da palavra ("Penetra surdamente no reino das palavras"). Lá estão a forma dificultada ("rolam num rio difícil") e a "forma definitiva e concentrada". Existem, porém, dois elementos nesse poema que gostaríamos de analisar um pouco mais detidamente, pois se prendem a dois conceitos que Tyniánov desenvolveu de modo bastante fecundo na segunda parte de seu livro. O primeiro deles é aquele "poder de palavra" contraposto ao "poder de silêncio" de Drummond, que Tyniánov chama de "equivalentes do texto". Claro que o alcance desse silêncio quase metafísico de Drummond é mais imediato em Tyniánov, mas vejamos o que ele diz a respeito.

Para Tyniánov, a ideia do verso como dado sonoro se encontra, antes de mais nada, diante da constatação de que alguns fatos essenciais da poesia não se esgotam na manifestação acústica do verso, pelo contrário, a ela se opõem. Entre eles estão os equivalentes de texto, ou seja, todos os elementos extraverbais que, de um modo ou de outro, o substituem: certas omissões parciais, certas substituições parciais por elementos gráficos e outros. O que é importante é verificar que o fenômeno dos equivalentes (de metro, de verso, de estrofe etc.) não implica atenuação ou relaxamento, mas pelo contrá- 
rio, implica pressão, tensão de elementos dinâmicos que não devem ser confundidos com a pausa, elemento homogêneo do discurso que ocupa um determinado lugar.

O último e mais crucial elemento que vamos abordar se prende mais literalmente ao sentido da palavra poética e vem introduzido pela penúltima estrofe do poema de Drummond:

Chega mais perto e contempla as palavras.

Cada uma

tem mil faces secretas sob a face neutra

e te pergunta, sem interesse pela resposta,

pobre ou terrivel, que lhe deres:

Trouxeste a chave? ${ }^{13}$

Pois bem, essas mil faces secretas que se escondem sob a face neutra da palavra são para Tyniánov os indícios de significado. Sem pretender desenvolvê-los, vamos apenas resumi-los utilizando, em alguns casos, os próprios exemplos de Tyniánov. Apagando-se o significado mais habitual da palavra (ou seja, o indício fundamental de seu significado) nela se manifesta mais fortemente seu matiz léxico, que é um indício secundário permanente de seu significado. Os indícios lexicais mais fortes aparecem nas palavras que não têm indícios fundamentais de significado: nomes próprios, barbarismos ou palavras simplesmente desconhecidas para o remetente. Curioso é um exemplo retirado de "Os mujiques", de Tchekhov:

Sacha levantou as sobrancelhas e começou alto, em tom de ladainha: - Partidos que foram, um anjo do Senhor apareceu em sonho a José dizendo: 'Levanta-te, pega o Menino e sua Mãe...' 'O Menino e sua Mãe' repetiu Olga corando de comoção. 'E foge para o Egito. Nesse ínterim...' à palavra 'Nesse ínterim'., Olga não se aguentou e desatou a chorar. ${ }^{14}$

13 Carlos Drummond de Andrade. "Procura da poesia". In: Rosa do povo. São Paulo: São Paulo: Companhia das Letras, 2012, p.12.

14 TCHEKHOV, Anton. "Os mujiques". In 0 assassinato e outras histórias. Trad. Rubens Figueiredo. São Paulo: Cosac \& Naify, 2011, p. 75. 
Este exemplo é um caso limite. Em poesia os indícios lexicais não eliminam os indícios fundamentais de significado, mas criam o assim chamado tom lexical, o qual, unido aos indícios flutuantes de significado (diferentes em cada caso), constitui o significado da palavra poética dentro de um dado contexto. A palavra não existe isolada, diz o autor. Mesmo que ela seja proferida isoladamente, fora de qualquer frase, é inevitável que provoque no ouvinte séries associativas. Os significados ocasionais que podem ser associados à palavra passam a funcionar como indícios secundários de significado que operam sobre o indício fundamental, dando origem a uma série de alterações. Assim, no trecho final de um poema de Marina Tsvetáieva (1917) traduzido ao francês por Elsa Triolet, temos as duas (ou mais) acepções da palavra "brumas" [brumes]:

...Ainsi, debout, mains dans les poches,

Avec l'ocean entre nous...

La ville dans les brumes,

Brumes anciennes de l'amour. ${ }^{15}$

Ou então outro exemplo, ainda da mesma autora: "Sobre os negros contornos do cabo/ A lua - armadura de cavaleiro".

Observa-se uma espécie de irradiação do significado dos elementos materiais e formais que constituem o signo / lua / e uma tendência a se orientarem para a determinação de um conceito. A matização da palavra "lua" não provém da anulação de seu indício fundamental, mas de sua permanência. Estamos diante de dois planos semânticos distintos, cada um dos quais tem seus indícios fundamentais e se equilibra com o plano paralelo. A flutuação dos dois planos semânticos pode ocasionar o obscurecimento parcial do indício fundamental, dando origem ao fenômeno que estamos acostumados a chamar de metáfora. Entre os indícios secundários manifestam-se alguns que, por sua instabilidade, foram chamados de

15 TSVÉTAIIÉVA, Marina. Poèmes (collection Poètes russes contemporains). Trad. de Elsa Triolet. Paris: Gallimard, 1968, p. 78. 
indícios flutuantes. De uma maneira geral, eles são frutos da ambiguidade entendida no sentido de William Empson: "Any verbal nuance which gives room for alternative reactions to the same piece of language."16

Esses indícios flutuantes podem estar ligados a fenômenos de som, como no "Conto do tsar Saltan" de Púchkin, agora, necessariamente, em russo:

I v sumú evó pustúiu

(E em sua bolsa vazia)

Súiut grámotu drugúiu

(Colocam outra ordem). ${ }^{17}$

Pode-se notar que o primeiro verso corresponde ao segundo com o grupo su (sumú - súiut) e uma sua repetição parcial é encontrada na palavra pustúiu. A extraordinária força expressiva do verso depende aqui da labialização do som [u]; a repetição deste som torna a articulação ainda mais forte na medida em que estas repetições dão o som não de forma monótona, mas pela alternância de seus diferentes matizes, o que produz uma impressão de articulação prolongada. Com isso os significantes das palavras passam a ser bastante deformados - é como se o indício fundamental da palavra sumú (bolsa), ligada sintática e foneticamente com pustúiu (vazia), por sua vez regressivamente ligada com súiut, retrocedesse diante de indícios flutuantes já perceptíveis. Assim, aqui agem não apenas o matiz semântico geral da série, mas também um deslocamento do significado da palavra, devido à sua estreita ligação rítmica com as outras palavras.

Um exemplo, entre muitos, que não poderia faltar, apresenta os indícios flutuantes ligados aos fenômenos de tom, que Tyniánov foi procurar em Montesquieu:

16 William Empson. 7 types of ambiguity. New York: New Direction, 1966.

17 Púchkin Apud TYNIÁNOV, lúri. O problema da linguagem poética II: o sentido da palavra poética. Rio de Janeiro: Tempo Brasileiro, 1975, p. 77. 
Centrenthus, Areca, Tegestas, Luscaris

Messanbrianthemum et Strutiopheris

Arthuriam, Raphis, Arecas et Limanthe... ${ }^{18}$

Temos aqui, ao lado de um tom lexical estável, dado pelo emprego de nomes próprios, também o surgimento de um tom transmental e, com a intensificação dos indícios flutuantes, a criação de uma semântica imaginária, tão cara aos futuristas russos, que com sua obra fornecem um campo inesgotável para a prática e a comprovação das teorias formalistas.

Para encerrar, eis como Tyniánov interpreta a "Encantação Pelo Riso" do Futurista Velímir Khébnikov, na tradução de Haroldo de Campos:

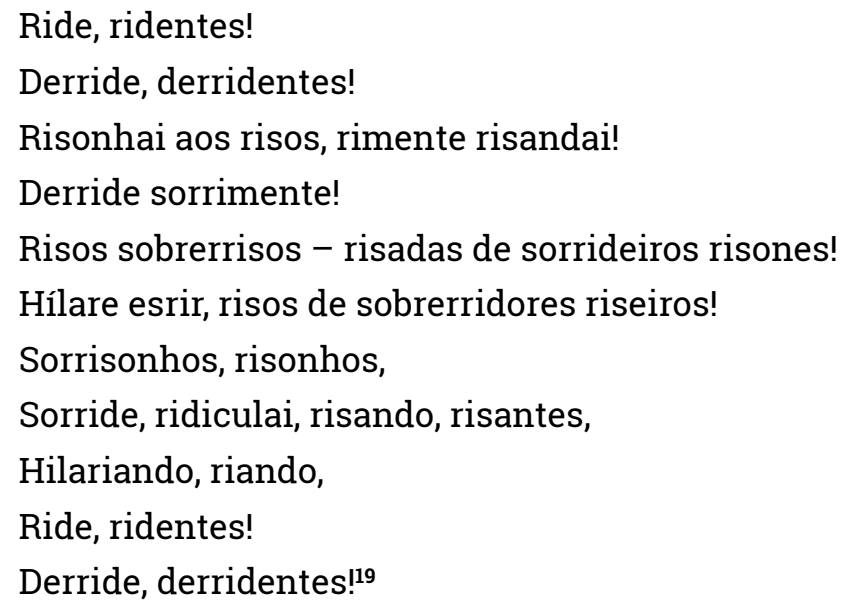

Vê-se aqui a intensificação do significado geral e o papel semântico considerável de cada palavra isolada. Com isso, pela importância do quadro sintático nesta diferenciação de palavras fundadas sobre uma parte objetiva comum, assumem importância também os próprios elementos formais das palavras, cuja semântica emerge tanto mais forte quanto mais a parte objetiva das palavras coincide. Esta coincidência impõe à parte objetiva individual de cada palavra uma relativa atenuação: seu significado é absorvido pelo significado geral e toda ênfase vai para as variantes da parte objetiva.

18 Montesquieu Apud TYNIÁNOV, lúri. O problema da linguagem poética II: o sentido da palavra poética. Rio de Janeiro: Tempo Brasileiro, 1975, p. 68. 


\section{Referências bibliográficas}

ANDRADE, Carlos Drummond de. Entrevista ao "Folhetim" de 03/06/1984 para o Jornal Folha de São Paulo.

ANDRADE, Carlos Drummond de. Rosa do povo. São Paulo: Companhia das Letras, 2012.

BANDEIRA, Manuel. Itinerário de Pasárgada. Rio de Janeiro: Nova Fronteira, 1966.

BRITTO, Paulo Henriques. "O Natural e o Artificial: Algumas Reflexões sobre o Verso Livre." ELyra: Revista Da Rede Internacional Lyracompoetics, (3). Obtido de https://www.elyra. org/index.php/elyra/article/view/40

CAMPOS, Haroldo; CAMPOS, Augusto; SCHNAIDERMAN, Boris. Poesia Russa Moderna. Rio de Janeiro. Civilização Brasileira, 1968.

EMPSON, William. 7 Types of Ambiguity. Nova York: New Directions, 1966.

JAKOBSON, Roman. Noveichaia russkaia poeziia (A novíssima poesia russa). Praga: Natchala, 1921.

JAKOBSON, Roman. Language in Literature. Cambridge (MA): Harvard University Press, 1990.

JAKOBSON, Roman. Linguística e comunicação. São Paulo: Cultrix, 1969.

POTEBNIÁ, Aleksandr. Iz lektsii po teorii slovesnosti: Basnia. Poslovitsa. Pogovorka (Das palestras sobre teoria da literatura: fábula, provérbio, ditos). Moscou: Vischa shkola, 1984, p. 99.

TCHEKHOV, Anton. $O$ assassinato e outras histórias. Trad. Rubens Figueiredo. São Paulo: Cosac \& Naify, 2011, pp. 75.

TSVÉTAIIÉVA, Marina. Poèmes (collection Poètes russes contemporains). Trad. Elsa Triolet. Paris: Gallimard, 1968.

TYNIÁNOV, Iuri. O problema da linguagem poética I: o ritmo como elemento construtivo do verso. Rio de Janeiro: Tempo Brasileiro, 1975. 
TYNIÁNOV, Iuri O problema da linguagem poética II: o sentido da palavra poética. Rio de Janeiro: Tempo Brasileiro, 1975.

TYNIANOV, Iúri. "El hecho literario", In: VOLEK, Emil (org. e trad.). Antología del formalismo Ruso y el grupo de Bajtin: polémica, historia y teoría literaria I. Madri: Fundamentos, 1992.

TYNIANOV, Iuri. "Sobre la evolución literaria”, In: VOLEK, Emil (org. e trad.). Antología del formalismo Ruso y el grupo de Bajtin: polémica, historia y teoría literaria I. Madri: Fundamentos, 1992.

TYNJANOV, Jurij. Il Problema del Linguaggio Poetico. Trad. Giovanni Giudici e di Ljudmila Kortikova. Milão: Mondadori, 1968.

VESSELÓVSKI, Aleksandr. Poética histórica. Trad. Pedro Piedras Monroy. Madri: Akal, 2014.

Recebido em: 24/06/2020

Aceito em: 11/08/2020

Publicado em setembro de 2020 